\title{
Spinal Nerve Root Hypertrophy on MRI: Clinical Significance in the Diagnosis of Chronic Inflammatory Demyelinating Polyradiculoneuropathy
}

\author{
Ko-ichi Tazawa ${ }^{1}$, Masayuki Matsuda ${ }^{1}$, Takuhiro Yoshida ${ }^{1}$, Yasuhiro Shimojima ${ }^{1}$, \\ Takahisa Gono ${ }^{1}$, Hiroshi Morita ${ }^{1}$, Tomoki Kaneko ${ }^{2}$, Hitoshi Ueda ${ }^{2}$ and Shu-ichi Ikeda ${ }^{1}$
}

\begin{abstract}
Objective To investigate the clinical usefulness of measuring diameters of spinal nerve roots on magnetic resonance imaging (MRI) in patients with chronic inflammatory demyelinating polyradiculoneuropathy (CIDP) with regard to the diagnosis and estimation of neurofunctional impairment.

Patients and Methods Fourteen patients with CIDP (mean age, 38.9 \pm 19.2 years) and 10 controls were enrolled in this study. Diameters of cervical and lumbosacral spinal nerve roots were determined on the short tau inversion recovery image of MRI. Correlations between these diameters and clinical indices, including the conduction velocity of median and tibial nerves, were examined.

Results Mean diameters of cervical and lumbosacral spinal nerve roots in CIDP patients were 6.0 to 6.8 $\mathrm{mm}$ and 7.3 to $10.4 \mathrm{~mm}$, respectively. CIDP patients showed higher values of the diameter in C5 $(\mathrm{p}<0.05)$, $\mathrm{C} 6(\mathrm{p}<0.05), \mathrm{C} 7(\mathrm{p}<0.005)$ and $\mathrm{C} 8(\mathrm{p}<0.01)$ than controls. C7 and C8 showed significantly negative correlations between diameters of spinal nerve roots and the F-wave conduction velocity (FWCV) $(\mathrm{p}<0.05)$. In the lumbosacral region, L3, L4 and S1 showed significantly negative correlations between diameters of spinal nerve roots and FWCV $(p<0.005, p<0.0005$ and $p<0.005$, respectively). The latency-time difference between F- and M-waves increased with diameters of spinal nerve roots, and there were significantly positive correlations between them in $\mathrm{L} 3(\mathrm{p}<0.05)$ and $\mathrm{L} 4(\mathrm{p}<0.005)$.

Conclusion Hypertrophy of spinal nerve roots shown on MRI may be useful as a clue to the diagnosis of CIDP and also as a clinical marker suggesting impairment of peripheral nerve conduction, particularly FWCV.
\end{abstract}

Key words: chronic inflammatory demyelinating polyradiculoneuropathy (CIDP), magnetic resonance imaging (MRI), spinal nerve root, hypertrophy, F-wave

(Inter Med 47: 2019-2024, 2008)

(DOI: 10.2169/internalmedicine.47.1272)

\section{Introduction}

Chronic inflammatory demyelinating polyradiculoneuropathy (CIDP) is a peripheral nerve disorder characterized clinically by sensori-motor disturbance of extremities with a relapse-remitting or slowly progressive course and pathologically by selective impairment of the myelin sheath, which can be detected by electrophysiological abnormalities such as slowing of nerve conduction velocities and conduction block $(1,2)$. Immune-mediated inflammation with localized production of cytokines is considered to play a central role in the pathogenesis of this disease, although the precise mechanisms remain unclear. According to several recent reports hypertrophy of spinal nerve roots is frequently seen in patients with CIDP, and detection of this finding with magnetic resonance imaging (MRI) or ultrasonography may be helpful in the diagnosis (3-12).

${ }^{1}$ Department of Internal Medicine (Neurology and Rheumatology), Shinshu University School of Medicine, Matsumoto and ${ }^{2}$ Department of Radiology, Shinshu University School of Medicine, Matsumoto

Received for publication May 1, 2008; Accepted for publication August 18, 2008

Correspondence to Dr. Masayuki Matsuda, matsuma@shinshu-u.ac.jp 
Table 1. Patient Profiles

\begin{tabular}{|c|c|c|c|c|c|c|c|c|c|}
\hline $\begin{array}{c}\text { Case } \\
\text { number }\end{array}$ & Sex & $\begin{array}{l}\text { Onset } \\
\text { age } \\
\text { (years) }\end{array}$ & $\begin{array}{l}\text { Nerve } \\
\text { biopsy }\end{array}$ & $\begin{array}{l}\text { Diagnosis } \\
\text { of CIDP* }\end{array}$ & $\begin{array}{l}\text { Disease } \\
\text { duration } \\
\text { at the study } \\
\text { (months) }\end{array}$ & $\begin{array}{c}\text { Anti-ganglioside } \\
\text { antibody in serum }\end{array}$ & $\begin{array}{l}\text { Anti-SGPG } \\
\text { IgM antibody } \\
\text { in sera }\end{array}$ & $\begin{array}{l}\text { Complications } \\
\text { at the study }\end{array}$ & $\begin{array}{c}\text { Treatment } \\
\text { performed } \\
\text { before the study }\end{array}$ \\
\hline 1 & $\mathrm{M}$ & 37 & + & definite & 40 & - & - & - & - \\
\hline 2 & M & 40 & + & definite & 72 & - & + & - & IVIG, IA \\
\hline 3 & M & 54 & + & definite & 36 & - & - & $\mathrm{DM}$ & IVIG \\
\hline 4 & $\mathrm{~F}$ & 53 & + & probable & 120 & - & - & $\mathrm{HCV}$ infection & IVIG, IA \\
\hline 5 & $\mathrm{~F}$ & 22 & - & probable & 48 & - & - & - & - \\
\hline 6 & M & 31 & - & probable & 72 & - & - & glaucoma & PSL, IVIG, AZT \\
\hline 7 & $\mathrm{~F}$ & 41 & - & probable & 78 & - & - & - & - \\
\hline 8 & M & 44 & - & probable & 24 & - & - & - & - \\
\hline 9 & M & 34 & + & definite & 36 & - & - & - & - \\
\hline 10 & M & 49 & - & probable & 24 & - & - & - & - \\
\hline 11 & M & 64 & + & definite & 6 & - & - & - & - \\
\hline 12 & M & 48 & + & definite & 60 & - & - & - & - \\
\hline 13 & F & 68 & + & definite & 36 & - & - & - & - \\
\hline 14 & F & 10 & - & probable & 18 & - & - & - & - \\
\hline
\end{tabular}

In this report we investigated the possible relationship between clinical indices, including electrophysiological parameters, and spinal nerve root diameters measured on MRI in patients with CIDP. F-wave conduction velocities (FWCV) decreased in parallel with an increase in diameters of some spinal nerve roots, and we suggest that MRI may be useful in the diagnosis of CIDP as it easily displays the hypertrophy of spinal nerve roots, and also in the estimation of neurofunctional impairment.

\section{Patients and Methods}

\section{Patients}

We studied 14 patients with CIDP who had been admitted to our hospital between April 1998 and June 2005 (9 men and 5 women; age range, 12 to 71 years; mean, $46.5 \pm 15.7$ years). They were diagnosed as having probable or definite CIDP following the criteria of the American Academy of Neurology AIDS Task Force (13). Patient profiles are summarized in Table 1. Mean disease duration was $4.0 \pm 2.5$ years, and all patients showed a chronic progressive course. Anti-ganglioside and anti-sulphoglucuronyl paragloboside (SGPG) IgM antibodies in serum were determined by enzyme-linked immunosorbent assay (ELISA) in all patients (14); the former was negative in all cases while the latter showed a positive result only in case 2 . In this patient, however, IgM paraproteinemia could not be confirmed on immunofixation. There were no preceding complications other than well-controlled diabetes mellitus in case 3, hepatitis $\mathrm{C}$ infection in case 4 and glaucoma in case 6 . In 4 patients various immunomodulatory treatments had been performed before this study: high-dose intravenous immunoglobulin (IVIG) in 4 cases, oral prednisolone in 1, immunoadsorption in 2 and azathioprine in 1. IVIG was effective for neurological symptoms, especially muscle weakness in the extremities, in case 2 but frequent administration was necessary at an extremely high cost in order to maintain the remission.
The remaining 10 patients had not received any treatment for CIDP before this study. Total protein and $\operatorname{IgG}$ in the cerebrospinal fluid (CSF) were determined in all the patients, and other clinical information was obtained from their medical records. We enrolled 6 healthy subjects $(6 \mathrm{men}$; age range, 32 to 46 years; mean, $39.6 \pm 5.7$ years) and 4 patients with other neurological disorders (OND) consisting of hysteria, multisystem atrophy, spinal subdural vein dilatation and Parkinson's disease ( 1 man and 3 women; age range, 16 to 62 years; mean, $49.3 \pm 22.3$ years) as controls. Body surface areas of the CIDP patients and controls were 1.693 \pm 0.066 and $1.710 \pm 0.071$, respectively, and there was no significant difference between them. The Local Ethical Committee approved this study.

\section{Electrophysiological studies}

Electrophysiological studies were carried out in median and tibial nerves of the side predominantly affected in the patients with CIDP. An active surface electrode was placed on the muscle belly and a reference electrode on the distal tendon to record the compound muscle action potential (CMAP) of the abductor pollicis brevis muscle (APB) and abductor hallucis longus muscle (AHL). The median nerve was stimulated at the wrist $(7.0 \mathrm{~cm}$ proximal to the active recording electrode over the APB) and elbow, with supramaximal electrical shock in order to evoke the distal and proximal CMAP (the maximal M-response), respectively. The size and terminal latency of CMAP of the APB, maximal motor nerve conduction velocity (MCV), latency-time difference between F- and M-waves, and conduction velocity and frequency of the F-wave were measured at the same time. Also in the tibial nerve these parameters were recorded at the AHL in the same manner with stimulation at the ankle (internal malleolus, $10.0 \mathrm{~cm}$ proximal to the active recording electrode over the AHL) and knee (popliteal fossa). The maximal sensory nerve conduction velocity (SCV) of both the median and tibial nerves was measured using the direct method, because sensory nerve action potentials in the 
patients were too small to record with surface electrodes in the usual antidromic manner. The stimulating surface ring electrodes were placed on the second finger and the third toe, and pairs of needle recording electrodes were insulated at the wrist, elbow, internal malleolus, and popliteal fossa. In this manner we could obtain precise measurements of the SCV of both distal areas (finger-wrist and toe-ankle) and proximal areas (wrist-elbow and ankle-knee).

\section{MRI}

MRI was performed in all of the patients and controls using a Siemens 1.5-T imager (Siemens, Erlangen, Germany) in order to obtain 3-mm-thick sections of coronal and axial views in cervical and lumbosacral spines. After the outlet of the intervertebral canal was found on the axial view, the coronal section of short tau inversion recovery (STIR) image through this level was scanned by an EPSON ES-8500 scanner (Epson, Tokyo, Japan), and transferred to a TV screen. The vertical length of each spinal nerve root was measured at the outlet of the intervertebral canal using commercially available software (MacSCOPE 9, Mitani, Fukui, Japan) (Fig. 1), and was defined as the diameter. Electrophysiological studies were performed in extremities of either the left or right side as described above, and the diameter of spinal nerve roots on the same side was used for analyses.

\section{Statistics}

To determine statistically significant differences between the patients and controls, the Kruskal Wallis test was employed for diameters of spinal nerve roots. We determined the best cut-off value of each spinal nerve root using the receiver-operating characteristic analysis in order to distinguish CIDP patients from controls. Correlation between diameters of spinal nerve roots and clinical indices, including electrophysiological parameters, was analyzed by Spearman's correlation test. The results represent the mean \pm standard deviation where applicable, and a p-level of less than 0.05 was considered to be statistically significant. Commercially available statistics software was used for data analysis (StatView for Macintosh, Abacus Concepts, Berkeley, CA, USA and Excel for Windows, Microsoft, Redmond, WA, USA).

\section{Results}

Diameters of each spinal nerve root are shown in Table 2. Mean values of the diameter of cervical spinal nerve roots in patients with CIDP ranged from 6.0 to $6.8 \mathrm{~mm}$. CIDP patients showed significant increases in $\mathrm{C5}(\mathrm{p}<0.05), \mathrm{C} 6(\mathrm{p}<$ $0.05), \mathrm{C} 7(\mathrm{p}<0.005)$ and $\mathrm{C} 8(\mathrm{p}<0.05)$ compared with OND and healthy subjects. The receiver-operating characteristic analysis indicated that $5.0 \mathrm{~mm}$ was the best cut-off value of spinal nerve root diameters in $\mathrm{C} 6, \mathrm{C} 7$ and $\mathrm{C} 8$ to distinguish CIDP patients from controls. Lumbosacral spinal nerve roots could be easily identified on MRI in CIDP patients but not in either OND or healthy subjects. Precise diameters of lum- bosacral spinal nerve roots could not be obtained in either OND or healthy subjects because of the lack of clear images. Mean values of the diameter of lumbosacral spinal nerve roots in CIDP patients ranged from 7.3 to $10.4 \mathrm{~mm}$.

Correlations between diameters of each spinal nerve root and various clinical indices are shown in Table 3. In the cervical region, $\mathrm{C} 7$ and $\mathrm{C} 8$ showed significantly negative correlations between diameters of spinal nerve roots and FWCV $(\mathrm{p}<0.05)$. There were no significant correlations between electrophysiological indices and diameters of spinal nerve roots in any other cervical regions. In the lumbosacral region, L3 and L4 showed significantly negative correlations between the diameters of spinal nerve roots and FWCV ( $p<0.005$ and $p<0.0005$, respectively) or the CMAP size ratio $(\mathrm{p}<0.005$ and $\mathrm{p}<0.01)$. A significantly negative correlation between diameters of spinal nerve roots and FWCV was seen also in $\mathrm{S} 1 \quad(\mathrm{p}<0.005)$. The latency-time difference between F- and M-waves increased with the diameters of spinal nerve roots, and there were significantly positive correlations between these in L3 $(\mathrm{p}<0.05)$ and L4 $(\mathrm{p}<0.005)$. Total protein and IgG in CSF and disease duration tended to increase in parallel with diameters of spinal nerve roots, but there were no significant correlations between them. MRI of spinal nerve roots and electrophysiological studies were serially performed only in case 2 . Despite amelioration of clinical symptoms, particularly sensory disturbance, soon after IVIG, this patient did not show either a decrease in diameters of spinal nerve roots or obvious improvement in electrophysiological indices.

\section{Discussion}

To determine the diameters of spinal nerve roots in the present study, we employed the STIR image of MRI, which could clearly demonstrate enlarged nervous tissues as a high signal with complete fat suppression. Nevertheless, these high signals shown on MRI include dura mater and cerebrospinal fluid, and their diameters are usually larger than the actual size of spinal nerve roots. An anatomical study in 20 cadavers without neurological disorders has demonstrated that mean diameters of $\mathrm{C} 6$ and $\mathrm{C} 7$ are $3.8 \mathrm{~mm}$ and $3.7 \mathrm{~mm}$, respectively (15). Considering that mean diameters of C6 and $\mathrm{C} 7$ in healthy subjects in the present study were 4.5 $\mathrm{mm}$ and $4.3 \mathrm{~mm}$, respectively, components other than the nervous tissue probably occupy 0.6 to $0.7 \mathrm{~mm}$ of the total diameter of spinal nerve roots shown on MRI.

There are two notable points in the present study. One is that the patients classifiable as probable or definite CIDP according to the established criteria for diagnosis showed significant enlargement of cervical and lumbosacral spinal nerve roots on MRI compared with controls. In the cervical region, $5.0 \mathrm{~mm}$ is considered as an adequate cut-off value of the spinal nerve root diameter discriminating CIDP patients from controls. Lumbosacral spinal nerve roots in controls were unidentifiable on MRI in the present study. In normal adults, these nerve roots run obliquely downwards through 

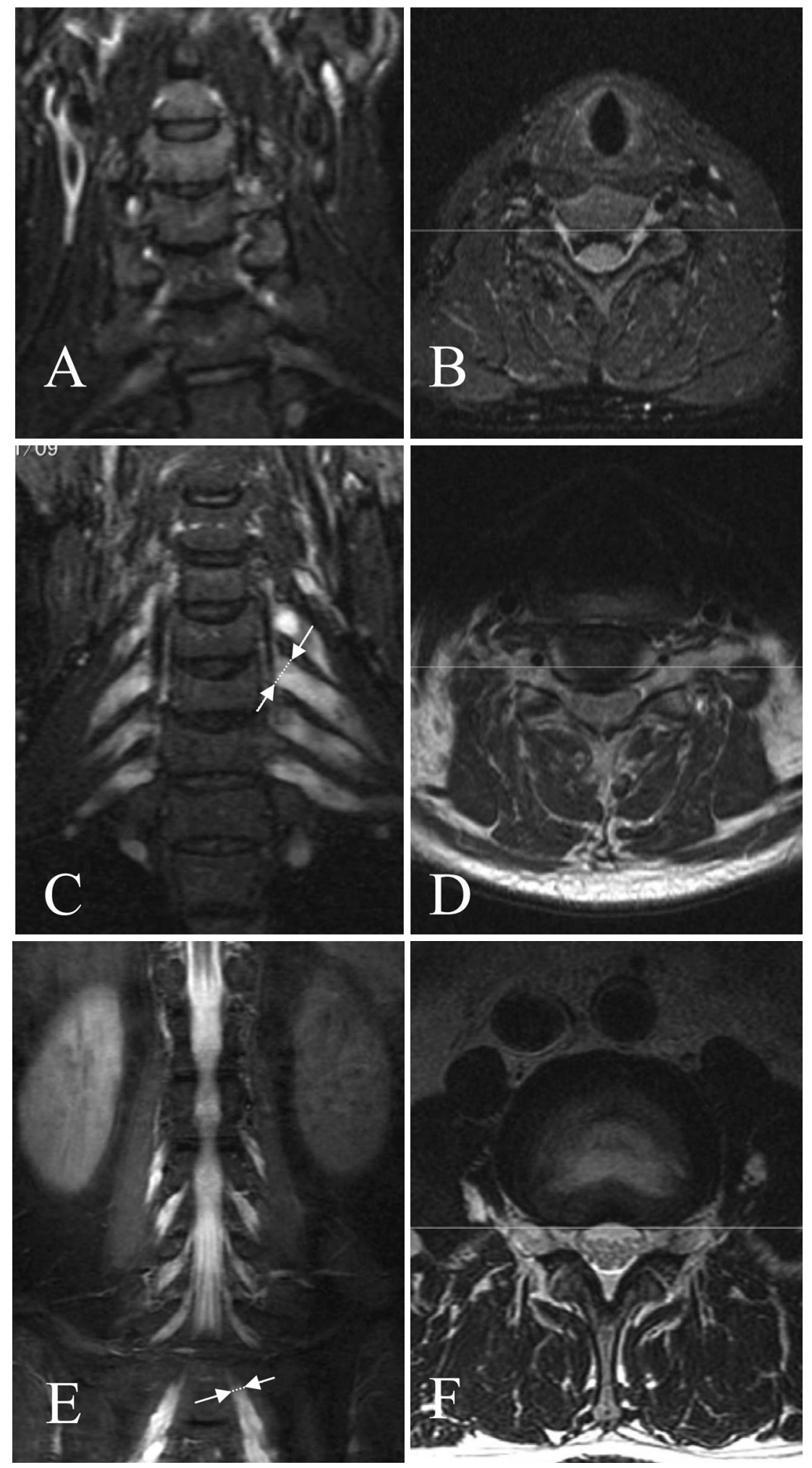

Figure 1. MRI of a control (A, B) and a representative case (case 2 in Table 1) of chronic inflammatory demyelinating polyradiculoneuropathy (C-F). The latter showed marked hypertrophy of spinal nerve roots in cervical $(C, D)$ and lumbar regions $(E, F)$. At first, the outlet of the intervertebral canal was identified on the axial image (annotation lines in B, D and F), and the coronal image was selected through this level (A, C and E). We defined a longitudinal axis of the nerve root, and measured its vertical length (arrows). A: short tau inversion recovery (STIR) image, TR/TE/TI=5770/56/140, B: STIR image, TR/TE/TI=5360/48/140, C: STIR image, TR/TE/TI= 5000/42/140, D: T2-weighted image, TR/TE=3272/72, E: STIR image, TR/TE/TI=4000/14/140, F: T2-weighted image, TR/TE=4000/92. 
Table 2. Diameters of Spinal Nerve Roots in Patients with CIDP and Controls

\begin{tabular}{|c|c|c|c|c|c|}
\hline \multirow{2}{*}{\multicolumn{2}{|c|}{$\begin{array}{l}\text { Spinal nerve } \\
\text { root }\end{array}$}} & \multicolumn{3}{|c|}{ Diameter (mm) } & \multirow[b]{2}{*}{$\mathrm{p}$ value } \\
\hline & & $\begin{array}{c}\text { Patients with } \\
\text { CIDP }\end{array}$ & OND & $\begin{array}{l}\text { Healthy } \\
\text { subjects }\end{array}$ & \\
\hline \multirow[t]{4}{*}{ Cervical } & $\mathrm{C} 5$ & $6.0 \pm 1.5$ & $3.7 \pm 0.1$ & $3.6 \pm 0.2$ & 0.049 \\
\hline & C6 & $6.8 \pm 1.5$ & $4.3 \pm 0.3$ & $4.5 \pm 0.4$ & 0.012 \\
\hline & $\mathrm{C} 7$ & $6.7 \pm 1.3$ & $4.0 \pm 0.5$ & $4.3 \pm 0.4$ & 0.002 \\
\hline & $\mathrm{C} 8$ & $6.7 \pm 1.8$ & $3.9 \pm 0.6$ & $5.0 \pm 0.2$ & 0.02 \\
\hline \multirow{5}{*}{$\begin{array}{c}\text { Lumbo- } \\
\text { sacral }\end{array}$} & L2 & $7.3 \pm 1.8$ & ND & ND & \\
\hline & L3 & $7.6 \pm 2.3$ & ND & ND & \\
\hline & L4 & $8.9 \pm 3.7$ & ND & ND & \\
\hline & L5 & $10.0 \pm 4.6$ & ND & ND & \\
\hline & $\mathrm{S} 1$ & $10.4 \pm 4.0$ & ND & ND & \\
\hline
\end{tabular}

ND: not detectable, OND: other neurological disease

Table 3. Correlation between the Diameter of Spinal Nerve Roots and Clinical Indices

\begin{tabular}{|c|c|c|c|c|c|c|c|c|c|c|c|c|}
\hline & \multicolumn{3}{|c|}{$\mathrm{C} 5$} & \multicolumn{3}{|c|}{ C6 } & \multicolumn{3}{|c|}{$\mathrm{C} 7$} & \multicolumn{3}{|c|}{$\mathrm{C} 8$} \\
\hline & Slope & $\mathrm{r}$ & $\mathrm{p}$ & Slope & $\mathrm{r}$ & $\mathrm{p}$ & Slope & $\mathrm{r}$ & $\mathrm{p}$ & Slope & $\mathrm{r}$ & $\mathrm{p}$ \\
\hline$\overline{\mathrm{MCV}}$ & -1.94 & 0.09 & 0.39 & 2.71 & 0.08 & 0.39 & -2.51 & 0.21 & 0.22 & -2.44 & 0.17 & 0.28 \\
\hline Terminal latency & -0.02 & 0.11 & 0.37 & -0.93 & 0.36 & 0.10 & 0.81 & 0 & 0.50 & 0.59 & 0.12 & 0.34 \\
\hline $\begin{array}{l}\text { CMAP size ratio (proximal } \\
\text { CMAP/distal CMAP) }\end{array}$ & 0.27 & 0.31 & 0.17 & 1.56 & 0.17 & 0.27 & -0.99 & 0.06 & 0.41 & -0.73 & 0.004 & 0.49 \\
\hline $\begin{array}{l}\text { Latency-time difference } \\
\text { between F-and M-waves }\end{array}$ & 0.47 & 0.28 & 0.52 & -1.68 & 0.13 & 0.47 & 5.09 & 0.39 & 0.47 & 1.84 & 0.09 & 1.84 \\
\hline F-wave conduction velocity & -7.33 & 0.43 & 0.12 & -2.37 & 0.15 & 0.49 & -7.12 & 0.55 & 0.03 & -5.82 & 0.49 & 0.048 \\
\hline Frequency of F-waves & -13.6 & 0.48 & 0.07 & 5.45 & 0.24 & 0.19 & 5.70 & 0.18 & 0.26 & 6.45 & 0.39 & 0.09 \\
\hline SCV distal part & -0.73 & 0.05 & 0.45 & 3.61 & 0.44 & 0.06 & -2.02 & 0.10 & 0.37 & -1.80 & 0.04 & 0.45 \\
\hline SCV proximal part & $\begin{array}{l}-1.7 \\
\end{array}$ & 0.10 & 0.38 & 3.39 & 0.22 & 0.22 & -3.18 & 0.12 & 0.38 & -3.08 & 0.24 & 0.20 \\
\hline Duration of disease & 0.73 & 0.38 & 0.12 & 0.14 & 0.22 & 0.22 & 0.30 & 0.32 & 0.13 & 0.12 & 0.14 & 0.31 \\
\hline Total protein in CSF & 10.6 & 0.33 & 0.17 & 17.4 & 0.29 & 0.16 & 15.3 & 0.21 & 0.24 & 6.98 & 0.096 & 0.37 \\
\hline IgG in CSF & 1.74 & 0.48 & 0.08 & 3.33 & 0.27 & 0.81 & 3.2 & 0.37 & 0.11 & 1.8 & 0.31 & 0.15 \\
\hline
\end{tabular}

\begin{tabular}{|c|c|c|c|c|c|c|c|c|c|c|c|c|c|c|c|}
\hline & \multicolumn{3}{|c|}{$\mathrm{L} 2$} & \multicolumn{3}{|c|}{ L3 } & \multicolumn{3}{|c|}{ L4 } & \multicolumn{3}{|c|}{ L5 } & \multicolumn{3}{|c|}{ S1 } \\
\hline & Slope & $\mathrm{r}$ & $\mathrm{p}$ & Slope & $\mathrm{r}$ & $\mathrm{p}$ & Slope & $\mathrm{r}$ & $\mathrm{p}$ & Slope & $\mathrm{r}$ & $\mathrm{p}$ & Slope & $\mathrm{r}$ & $\mathrm{p}$ \\
\hline$\overline{\mathrm{MCV}}$ & -4.70 & 0.06 & 0.45 & -2.27 & 0.48 & 0.12 & -1.95 & 0.55 & 0.08 & -0.29 & 0.04 & 0.47 & 0.79 & 0.43 & 0.20 \\
\hline Terminal latency & -0.65 & 0.19 & 0.32 & -0.44 & 0.27 & 0.24 & -0.31 & 0.20 & 0.31 & -0.29 & 0.69 & 0.03 & -0.54 & 0.66 & 0.07 \\
\hline $\begin{array}{l}\text { CMAP size ratio (proximal } \\
\text { CMAP/distal CMAP) }\end{array}$ & -0.52 & 0.05 & 0.45 & -4.89 & 0.81 & 0.003 & -1.96 & 0.76 & 0.008 & -0.38 & 0.16 & 0.34 & 0.03 & 0.25 & 0.31 \\
\hline $\begin{array}{l}\text { Latency-time difference } \\
\text { between F-and M-waves }\end{array}$ & 4.88 & 0.53 & 0.17 & 4.98 & 0.82 & 0.02 & 2.74 & 0.92 & 0.004 & 1.70 & 0.54 & 0.13 & 1.24 & 0.8 & 0.09 \\
\hline$\overline{\text { F-wave conduction velocity }}$ & -5.10 & 0.79 & 0.053 & -4.81 & 0.94 & 0.002 & -2.62 & 0.97 & 0.0003 & -1.67 & 0.65 & 0.078 & -1.14 & 1.0 & 0.001 \\
\hline Frequency of F-waves & 2.39 & 0.02 & 0.48 & 3.73 & 0.12 & 0.38 & 1.72 & 0.11 & 0.39 & 0.29 & 0.07 & 0.43 & -0.66 & 0.36 & 0.27 \\
\hline SCV distal part & 2.78 & 0.12 & 0.39 & 1.57 & 0.28 & 0.23 & 1.37 & 0.40 & 0.14 & 1.27 & 0.52 & 0.09 & 1.65 & 0.48 & 0.16 \\
\hline SCV proximal part & 3.93 & 0.57 & 0.09 & 1.89 & 0.26 & 0.27 & 1.53 & 0.17 & 0.34 & 1.50 & 0.62 & 0.051 & 2.43 & 0.54 & 0.13 \\
\hline Duration of disease & 0.02 & 0.46 & 0.13 & 0.11 & 0.16 & 0.34 & 0.10 & 0.33 & 0.19 & 0.04 & 0.07 & 0.43 & -0.10 & 0.02 & 0.47 \\
\hline Total protein in CSF & 16.4 & 0.05 & 0.45 & 4.87 & 0.03 & 0.47 & 6.45 & 0.05 & 0.45 & 6.98 & 0.45 & 0.13 & 8.26 & 0.25 & 0.31 \\
\hline $\mathrm{IgG}$ in $\mathrm{CSF}$ & 4.70 & 0.11 & 0.39 & 0.11 & 0.16 & 0.34 & 0.10 & 0.33 & 0.19 & 0.04 & 0.07 & 0.43 & 2.30 & 0.42 & 0.19 \\
\hline
\end{tabular}

the subarachnoid space to the foramina due to differential growth between the spinal cord and vertebral column (16). Lumbosacral spinal nerve roots may be more distal and thinner than cervical ones at the outlet of the intervertebral canal, where we measured diameters in the present study. In cases clearly showing lumbosacral spinal nerve roots on the STIR image of MRI, therefore, hypertrophic change should be strongly suspected. Several reports have also demonstrated that hypertrophic change on MRI is frequently seen in cervical spinal roots, brachial plexus and cauda equina of CIDP patients (3-12). These findings suggest that hypertrophic change on MRI may be an important clue indicating CIDP. Several other disorders, such as lymphoma and hereditary neuropathies, have also been reported to show hypertrophy of spinal nerve roots $(17,18)$, and further investigations are necessary in order to clarify whether or not these findings on MRI are useful in the differential diagnosis of peripheral nerve impairment.

The other notable point is that hypertrophic change of spinal nerve roots was significantly correlated with some electrophysiological indices. FWCV of median and tibial nerves showed significantly negative correlations with diameters of spinal nerve roots in $\mathrm{C} 7$ and $\mathrm{C} 8$ and in L3, L4 and $\mathrm{S} 1$, respectively. In L3 and L4, the CMAP size ratio of the tibial nerve was also significantly decreased in parallel with an increase in diameters of spinal nerve roots. There was a significantly positive correlation between the latencytime difference between $\mathrm{F}$ - and $\mathrm{M}$-waves in the tibial nerve and diameters of spinal nerve roots in L3 and L4. Considering that the median and tibial nerves, in which electrophysiological examinations were performed, arise from C5 to Th1 and from L3 to S3 $(19,20)$, respectively, these results suggest that hypertrophic change shown on MRI may reflect severe impairment of peripheral nerve conduction, although in 
the present study we did not evaluate diameters of S2 and S3, which mainly distribute to the sole and the lateral side of the feet, including AHL (21). According to several recent reports hypertrophic change of spinal nerve roots is attributable to infiltration of inflammatory cells, interstitial edema and onion-bulb formation due to repeated demyelination and remyelination $(9,22)$, and frequently produces conduction block $(7,9)$. Total protein in CSF has been reported to show a significantly positive correlation with diameters of spinal nerve roots (10), but in the present study we could not find such a relationship between them. This may be due to the immunomodulatory treatments performed in 4 patients of the present study before measuring diameters of spinal nerve roots on MRI.
In conclusion, MRI study of spinal nerve roots contributes to the diagnosis of CIDP because of easy detection of hypertrophy. The diameters of spinal nerve roots correlate well with certain electrophysiological indices, particularly FWCV, and may be a helpful parameter in estimating impairment of nerve conduction.

\section{Acknowledgement}

The authors are grateful to Drs. K. Susuki and N. Yuki, Department of Neurology, Dokkyo University School of Medicine, for determination of anti-ganglioside and anti-SGPG antibodies by ELISA. This work was supported by a grant from Neuroimmunological Disease Division, the Ministry of Public Health, Labor and Welfare, Japan.

\section{References}

1. Latov N. Diagnosis of CIDP. Neurology 59 (Suppl. 6): S2-S6, 2002.

2. Sander HW, Latov N. Research criteria for defining patients with CIDP. Neurology 60 (Suppl. 3): S8-S15, 2003.

3. Crino PB, Grossman RI, Rostami A. Magnetic resonance imaging of the cauda equina in chronic inflammatory demyelinating polyneuropathy. Ann Neurol 33: 311-313, 1993.

4. Morgan GW, Barohn RJ, Basan III C, King BB, Klueznik RP. Nerve root enhancement with MRI in inflammatory demyelinating polyradiculoneuropathy. Neurology 43: 618-620, 1993.

5. De Silva RN, Willison HJ, Doyle D, Weir AI, Hadley DM, Thomas AM. Nerve root hypertrophy in chronic inflammatory demyelinating polyneuropathy. Muscle Nerve 17: 168-170, 1994.

6. Midroni G, Dyck PJ. Chronic inflammatory demyelinating polyradiculoneuropathy. Unusual feature and therapeutic responses. Neurology 46: 1206-1212, 1996.

7. Kuwabara S, Nakajima M, Matsuda S. Magnetic resonance imaging at the demyelinating foci in chronic inflammatory demyelinating polyneuropathy. Neurology 48: 874-877, 1997.

8. Duggins AJ, McLood JG, Pollard JD, et al. Spinal root and plexus hypertrophy in chronic inflammatory demyelinating polyneuropathy. Brain 122: 1383-1390, 1999.

9. Kaji R, Oka N, Tsuji T, et al. Pathological findings at the site of conduction block in multifocal motor neuropathy. Ann Neurol 35: 246-247, 1994.

10. Matsuoka N, Kohriyama T, Ochi K. Detection of cervical nerve root hypertrophy by ultrasonography in chronic inflammatory demyelinating polyradiculoneuropathy. J Neurol Sci 219: 15-21, 2004.

11. Gono T, Matsuda M, Shimojima Y, et al. Rituximab therapy in chronic inflammatory demyelinating polyradiculoneuropathy with anti-SGPG IgM antibody. J Clin Neurosci 13: 683-687, 2006.

12. Wilhelm LJT, King RHM, Ginsberg L, Orrel RW. Brachial plexus hypertrophy in chronic inflammatory demyelinating polyradicu- loneuropathy. Neuromusc Disord 16: 126-131, 2006.

13. Ad Hoc. Subcommittee of the American Academy of Neurology AIDS Task Force. Research criteria for diagnosis of chronic inflammatory demyelinating polyneuropathy (CIDP). Neurology 41: 617-618, 1991.

14. Tagawa Y, Yuki N, Hirata K. Anti-SGPG antibody in CIDP: nosological position of IgM anti-MAG/SGPG antibody-associated neuropathy. Muscle Nerve 23: 895-899, 2000.

15. Uğur HÇ, Attar A, Uz A, et al. Surgical anatomic evaluation of the cervical pedicle and adjacent neural structures. Nurosurgery 47: 1162-1169, 2000.

16. England MA, Wakely J. A Colour Atlas of the Brain \& Spinal Cord. An Introduction to Normal Neuroanatomy. Wolfe Publishing Ltd, London, 1991: 171.

17. Haubrich C, Krings T, Senderek J, et al. Hypertrophic nerve roots in a case of Roussy-Levy syndrome. Neuroradiology 44: 933-937, 2002.

18. Kumar N, Dyck PJ. Hypertrophy of the nerve roots of the cauda equina as a paraneoplastic manifestation of lymphoma. Arch Neurol 62: 1776-1777, 2005.

19. Snell RS. The upper limb. Brachial plexus. In: Clinical Anatomy by Regions. 8th ed. Wolters Kluwer/Lippincott Williams \& Wilkins, Philadelphia, 2007: 446-453.

20. Snell RS. The lower limb. Nerves of the gluteal region. In: Clinical Anatomy by Regions. 8th ed. Wolters Kluwer/Lippincott Williams \& Wilkins, Philadelphia, 2007: 565-566.

21. Snell RS. The foot. In: Clinical Anatomy by Regions. 8th ed. Wolters Kluwer/Lippincott Williams \& Wilkins, Philadelphia, 2007: 619-626.

22. Matsuda M, Ikeda S, Sakurai S, Nezu A, Yanagisawa N, Inuzuka T. Hypertrophic neuritis due to chronic inflammatory demyelinating polyradiculoneuropathy (CIDP): a postmortem pathological study. Muscle Nerve 19: 163-169, 1996.

(C) 2008 The Japanese Society of Internal Medicine

http://www.naika.or.jp/imindex.html 